\title{
Implementasi Metode K-Means Clustering pada Sistem Rekomendasi Dosen Tetap Berdasarkan Penilaian Dosen
}

\author{
Yessica Putri Santoso ${ }^{1}$, Marlina ${ }^{2}$, dan Halim Agung ${ }^{3}$ \\ 1,2,3 Teknik Informatika, Universitas Bunda Mulia, Jalan Lodan Raya No. 2, Jakarta Utara \\ e-mail: ${ }^{1}$ yessicaputrisantoso@gmail.com, ${ }^{2}$ mbunathan@gmail.com, ${ }^{3}$ hagung@bundamulia.ac.id
}

\begin{abstract}
Qualified lecturers can be one of the recommendations for lecturers to become permanent lecturers. The requirement to become a lecturer is to be able to teach, educate, and broaden the horizons of the students he teaches. One way to get qualified lecturers is to evaluate the performance of lecturers at the end of each semester, to find out whether the lecturer has a good performance or not. The use of the K-means clustering method as a system aide in determining lecturer recommendations will greatly assist the university in appointing lecturers as permanent lecturers. The way to work on the K-means clustering method is to find the centroid value in the value of each lecturer and in the process of getting a permanent lecturer candidate. In the results of the calculation of the K-means clustering method for 70 lecturers' assessment data in the system, which included a decent category there were 39 data. In this case, the success rate of the K-means clustering method was obtained at $55.71 \%$ success rate.
\end{abstract}

Kata Kunci: $k$-means clustering, lecturer, assessment, recommendation, university.

\section{PENDAHULUAN}

Pada UU nomor 14 tahun 2005, pengertian dosen adalah pendidik yang professional dan sebagai ilmuan yang tugas utamanya terdapat dalam tridharma perguruan tinggi.

Kualitas seorang dosen menentukan kualitasnya dalam mengajarkan ilmunya ke muridmuridnya. Di masa depan, Kebutuhan dari kualitas seorang manusia adalah yang mampu bersaing terhadap seluruh aspek yang ada di dunia. Oleh sebab itu, tenaga pengajar yang sering kita sebut sebagai dosen memiliki kedudukan, peran dan fungsi yang mampu mewujudkan cita-cita bangsa.

Maka itu, setiap kampus memiliki SOP (Standart Operating Procedure) terhadap penilaian dosen, yang di mana akan terus dievaluasi secara rutin dan berkala dalam memperoleh dosen yang memiliki kualifikasi yang baik. Selain itu, evaluasi bertujuan untuk menjaga kualitas sebuah institusi, dan mempermudah dalam mengambil kebijakan serta tindakan yang tepat untuk meningkatkan kualitas dosen, serta mempermudah dalam memberikan penugasan kepada dosen yang tepat (Wahyuningtyas, Putri, \& Sutrisno, 2018).

Universitas xyz melakukan evaluasi penilaian dosen setiap akhir semester untuk mengetahui dosen dengan hasil penilaian terbaik. Hasil penilaian dosen pada universitas xyz dilakukan sebagai penentu jabatan dosen yaitu dosen yang layak menjadi dosen tetap, penilaian pada universitas xyz masih kurang efektif dalam menentukan dosen tetap berdasarkan hasil penilaian dosen pada sistem.

Dalam hal ini diperlukan sistem penilaian dosen untuk membantu kaprodi dalam menentukan dosen tetap berdasarkan hasil penilaian yang didapatkan dosen melalui sistem. Hasil penilaian pada sistem akan diklaster menggunakan metode $K$-Means dalam menentukkan rekomendasi dosen yang layak menjadi dosen tetap.

\section{METODE PENELITIAN \\ Tinjuan Studi}

Penelitian yang dilakukan A Seetharam Nagesh dan Ch V S Satyamurty yang berjudul "Aplication of Clustering Algorithm for Analysis of Student Academic Performance" diperoleh hasil peneliti yang menganalisis data mahasiswa dan prediksi dari presentasi mahasiswa dalam performan akademik adalah buruk, rata-rata dan bagus. Dari $50 \%$ pengelompokkan data menunjukkan hasil yang bagus. Jika manajemen mengambil tindakan yang tepat utuk meningkatkan performan akademik mahasiswa dari mahasiswa untuk pengelompokkan rata-rata dan buruk. Di mana bisa digunakan untuk proses membuat keputusan dari manajemen untuk institusi edukasi. 


\section{K-Means Clustering}

K-Means Clustering adalah metode data cluster non-hirarki yang mengelompokkan data dalam bentuk satu atau lebih cluster dengan data yang hampir sama. Data yang memiliki karakteristik yang sama akan dikumpulkan dalam stau cluster, sedangkan data yang memiliki karakteristik berbeda akan dikumpulkan ke dalam cluster yang lain. Karakteristik data yang terbesar dalam satu cluster memiliki tingkat variasi yang kecil (Wahyuningtyas, Putri, \& Sutrisno, 2018).

Tahapan dalam melakukan clustering dengan metode $K$-Means adalah sebagai berikut (Ong, 2013) :

1. Pilih jumlah cluster $\mathrm{k}$.

2. Pemberian nilai k pusat cluster ini dapat dilakukan dengan berbagai cara dan salah satunya adalah secara random. Pusat cluster diberi nilai awal dengan angka acak.

3. Alokasikan semua data/objek pada cluster terdekat. Kedekatan dua objek ditentukan berdasarkan jarak kedua objek tersebut. Demikian juga kedekatan suatu data ke cluster tertentu ditentukan jarak antar data dengan pusat cluster. Dalam tahap ini perlu dihitung jarak tiap data ke tiap pusat cluster. Jarak antara satu data dengan satu cluster tertentu akan menentukan suatu data akan masuk ke dalam cluster yang mana. Rumus menghitung jarak data ke setiap titik pusat cluster bisa menggunakan jarak Euclidian Distance yang dituliskan dalam:

$$
D(i, j)=\sqrt{\left(X_{1 i}-Y_{1 j}\right)^{2}+\left(X_{2 i}-Y_{2 j}\right)^{2}+\cdots+\left(X_{k i}-Y_{k j}\right)^{2}}
$$

Di mana:

$$
\begin{array}{ll}
\mathrm{D}(i, j) & \text { : Jarak data ke } \mathrm{i} \text { ke pusat cluster } \mathrm{j} \\
\mathrm{X}_{\mathrm{ki}} & \text { : Data ke i pada atribut data ke } \mathrm{k} \\
\mathrm{Y}_{\mathrm{kj}} & \text { : Titik pusat ke } \mathrm{j} \text { pada atribut ke } \mathrm{k}
\end{array}
$$

4. Kalkulasi lagi pusat cluster dengan keanggotaan cluster yang sekarang. Pusat cluster adalah average dari semua data/objek dalam cluster tertentu dan bisa juga menggunakan media dari cluster tersebut.

5. Ulang lagi perintah bagi setiap objek untuk menggunakan pusat cluster yang baru. Jika pusat cluster tidak berubah lagi maka proses cluster selesai. Atau kembali ke langkah nomor 3 sampai pusat cluster tidak berubah lagi.

\section{Waterfall Model}

Waterfall Model merupakan model yang digunakan oleh para developer. Tahapan utama dari waterfall model menggambarkan aktivitas pengembangan dasar (Rosmiati, 2015).

Tahapan yang dilakukan pada perancangan sistem model waterfall sebagai berikut:

1. Requirement Analysis and Definition

Dalam tahapan ini, dilakukannya analisis akan kebutuhan penerapan fitur pada sistem hasil penilaian kinerja dosen agar dapat berjalan sesuai dengan tujuan sistem dibuat serta penetapan spesifikasi sistem dengan detail sebelum diterapkan dalam pembuatan sistem.

2. System and Software Design

Jika telah menentukan tujuan dan fitur yang diperlukan, maka sistem penilaian hasil kinerja dosen dapat di design agar memudahkan dalam pembuatan sistem. Design sistem ini dapat berupa alur proses atau alur sistem.

3. Implementation and Unit Testing Design yang telah dibuat diimplementasikan dalam bentuk aplikasi dan melakukan pemeriksaan fungsi yang terdapat pada aplikasi agar berjalan sesuai dengan tujuan.

4. Integration and System Testing

Setelah menjadi sebuah aplikasi, dilakukan pengujian terhadap sistem pengelompokan hasil penilaian kinerja dosen dengan memasukkan beberapa data penilaian dosen, dan sistem akan menguji data tersebut dan mengelompokkannya berdasarkan rekomendasi k-means.

5. Operation and Maintenance

Setelah aplikasi sudah diuji coba berkalikali untuk melihat apakah ada kesalahan atau tidak, maka aplikasi tersebut dapat dipasang dan digunakan. Jika selama penggunaan terdapat kekurangan atau terjadi masalah, maka akan dilakukan pengembangan dan perbaikan.

\section{Flowchart}

Flowchart adalah gambaran dari suatu algoritma atau prosedur yang digunakan dalam menyelesaikan suatu masalah, dengan menggunakan flowchart akan mempermudah pengguna melakukan evaluasi pada bagian yang terlupakan dalam hal analisis (Santoso \& Nurimalina, 2017). 


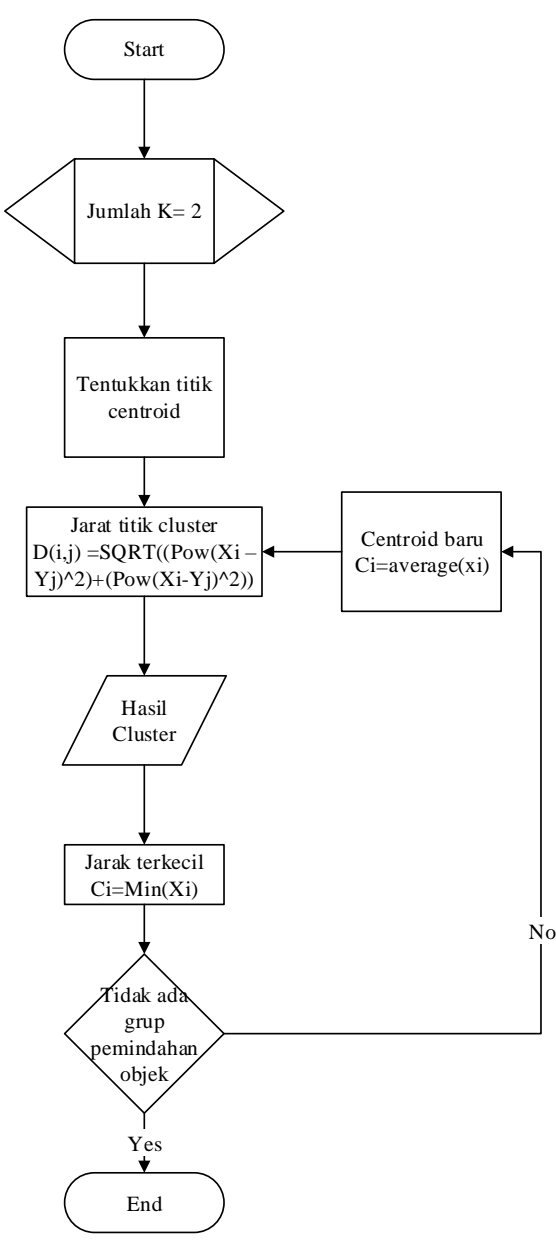

Gambar 1 Flowchart Algoritma K-Means

Pada Gambar 1 menjelaskan proses perhitungan $k$-means yang terjadi pada sistem, di mana jumlah kategori yang ditentukan adalah 2 . Setelah itu tentukan nilai centroid berdasarkan jumlah $\mathrm{k}$, hasil cluster dihasilkan dengan mencari jarak terkecil dari proses cluster, proses cluster akan berhenti sampai titik pada cluster tidak berpindah lagi per cluster.

\section{Use Case Diagram}

Use case diagram adalah cara untuk menggambarkan kelakuan sistem informasi yang akan dibangun. Use case digunakan untuk mengetahui fungsi yang berada di dalam sistem dan aktor yang di berikan ijin menggunakan fungsifungsi tersebut (Santoso \& Nurimalina, 2017).

Pada Gambar 2 Use case diagram pada sistem ini terdiri dari 5 actor yang dapat berinteraksi dengan sistem tetapi memiliki batas atau hanya berinteraksi dengan sistem yang dapat diaksesnya saja.

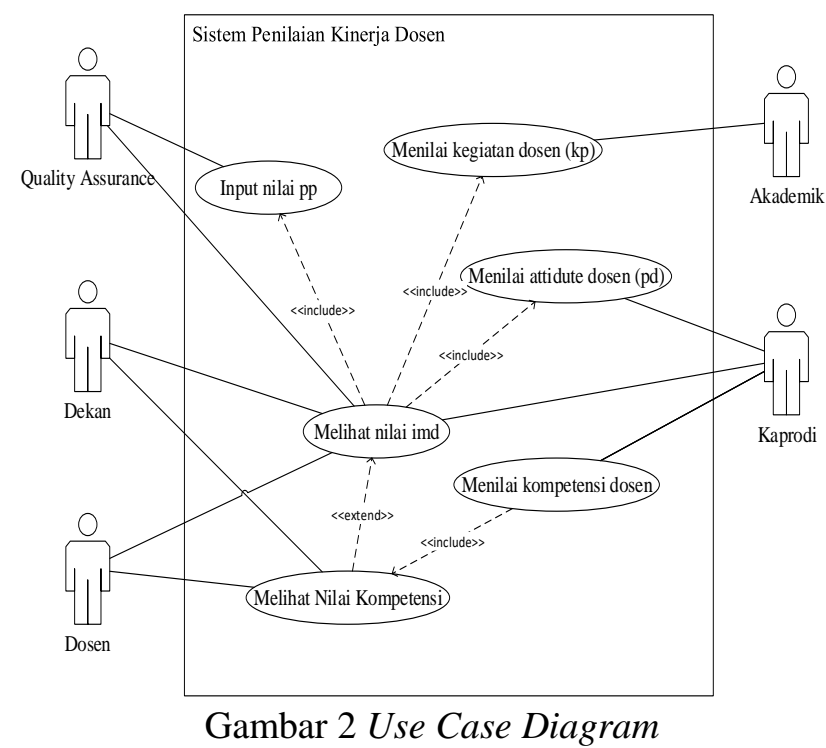

Activity Diagram

Activity diagram menggambarkan alur proses yang terjadi pada sistem. Berikut merupakan gambaran Activity Diagram:

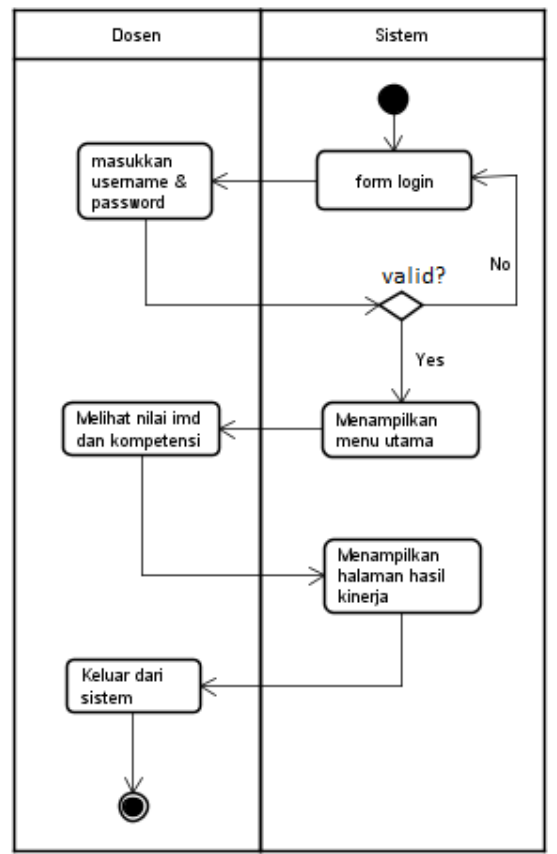

Gambar 3 Activity Sistem Pada Dosen

Pada Gambar 3 merupakan aktivitas dosen pada sistem, di mana saat dosen mulai berinteraksi dengan memasukan username dan password, apabila benar sistem akan menampilkan form utama, apabila salah sistem akan tetap pada form login. Setelah menampilkan form utama, dosen dapat melihat hasil kinerja yang dimiliki dosen tersebut, dan dosen dapat logout dari sistem. 


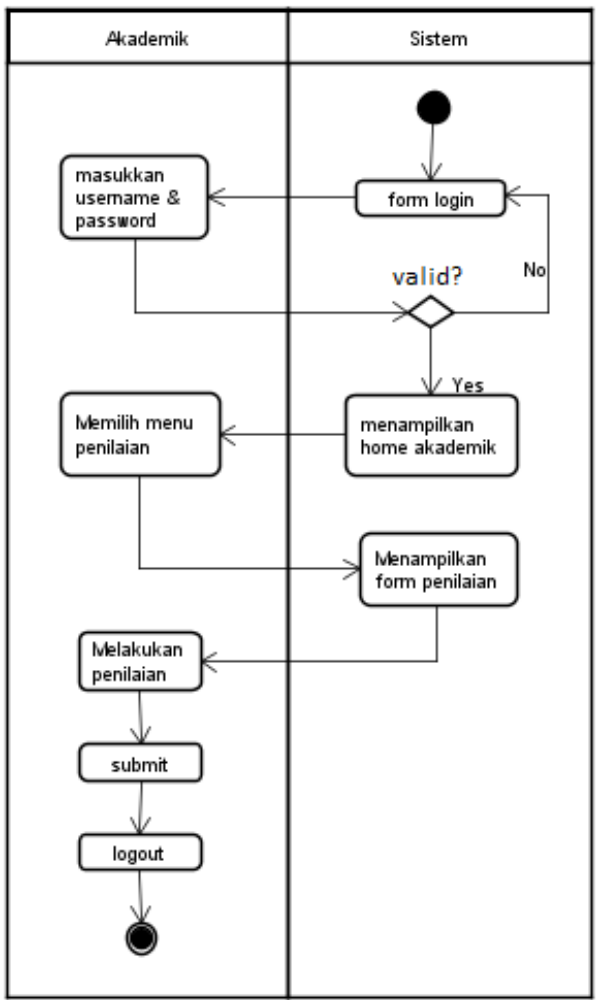

Gambar 4 Activity Sistem Pada Akademik

Pada gambar 4 merupakan aktivitas akademik pada sistem dalam menilai kegiatan pembelajaran dosen, di mana saat akademik berinteraksi dengan sistem, sistem akan menampilkan form login, akademik memasukkan username dan password apabila username dan password yang dimasukkan benar, maka sistem akan menampilkan form penilaian dosen, dan melakukan penilaian terhadap dosen lalu submit, sistem akan memproses penilaian tersebut. Akademik dapat logout dari sistem.

Pada Gambar 5 merupakan aktivitas Ketua Program Studi pada sistem dalam menilai attitude dosen, dan kompetensi, di mana saat Ketua Program Studi berinteraksi dengan sistem, sistem akan menampilkan form login, Setelah akun Ketua Program Studi terverifikasi dengan benar, maka sistem akan menampilkan form penilaian dosen, dan melakukan penilaian terhadap dosen lalu submit, sistem akan memproses penilaian tersebut. Ketua Program Studi dapat logout dari sistem.

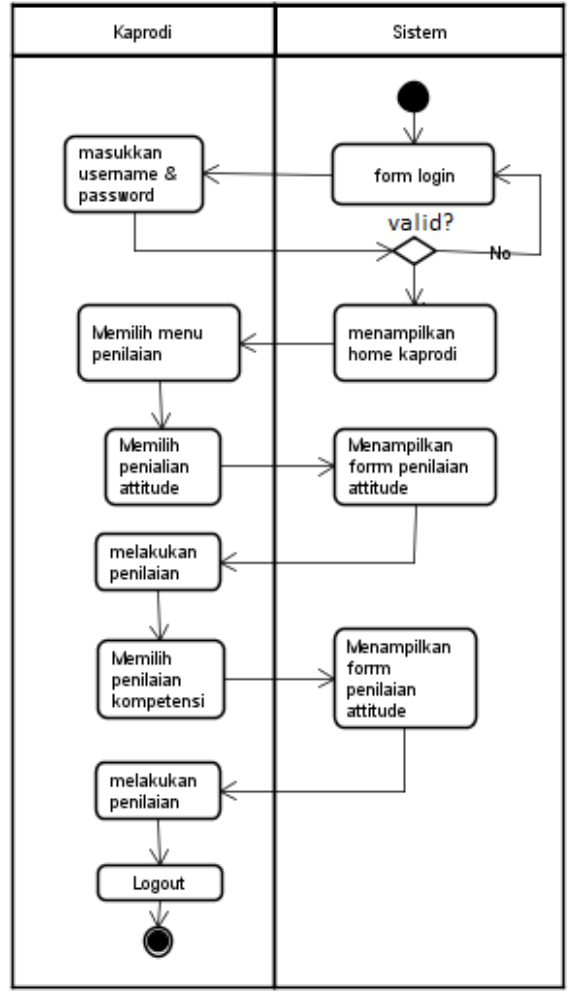

Gambar 5 Activity Sistem Pada Ketua Program Studi

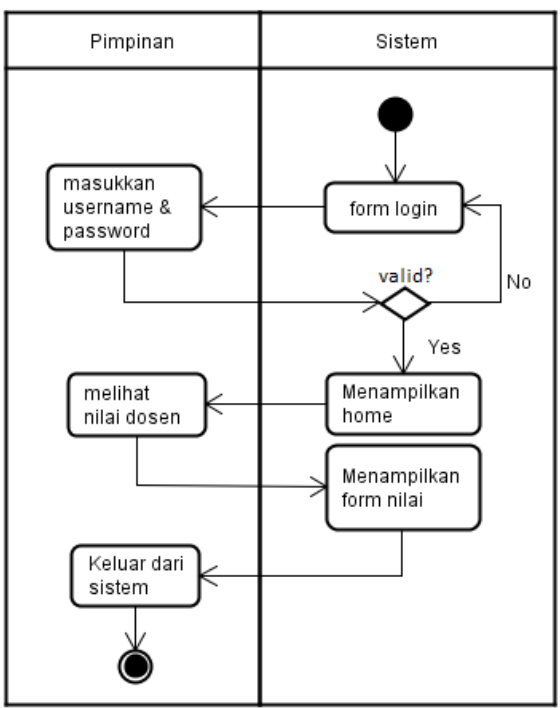

Gambar 6 Activity Sistem Pada Pimpinan

Pada Gambar 6 merupakan aktivitas pimpinan pada sistem dalam melihat nilai dosen, di mana saat pimpinan berinteraksi dengan sistem, sistem akan menampilkan form login, pimpinan memasukkan data akun nya kembali kemudian sistem akan menampilkan form nilai dosen. Pimpinan dapat logout dari sistem. 


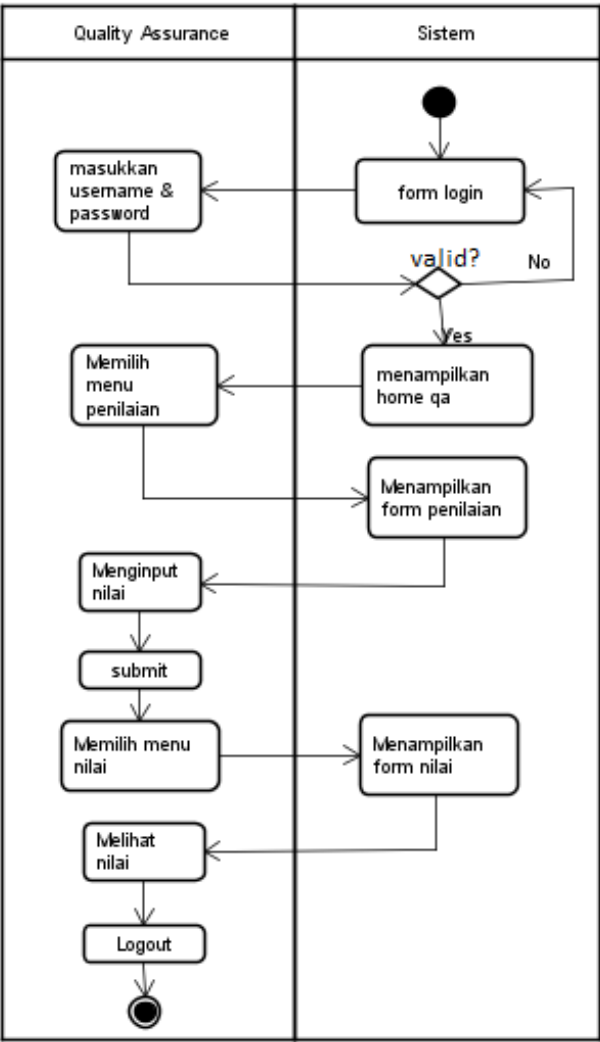

Gambar 7 Activity Sistem Pada Quality Assurance

Pada Gambar 7 merupakan aktivitas Quality Assurance pada sistem dalam memasukkan nilai pp dosen, dan melihat nilai indeks mengajar dosen, di mana saat Quality Assurance berinteraksi dengan sistem, kemudian sistem akan menampilkan form input nilai dosen, dan melakukan submit, sistem akan memproses penilaian tersebut. Quality Assurance dapat logout dari sistem.

\section{Sequence Diagram}

Sequence diagram merupakan kelakuan objek pada use case dengan mendeskripsikan waktu objek dan pesan dapat dikirimkan dan diterima objek.

Pada gambar 8 menjelaskan bahwa dosen dapat mengirimkan pesan ke objek lain dengan melakukan login, kemudian sistem akan menampilkan form hasil nilai dosen, dosen dapat melihat nilai, dan keluar dari sistem.

Pada gambar 9 merupakan interaksi akademik dengan objek yang ada pada sistem, di mana akademik melakukan login, kemudian sistem akan menampilkan form penilaian, akademik dapat melakukan penilaian, dan keluar dari sistem.

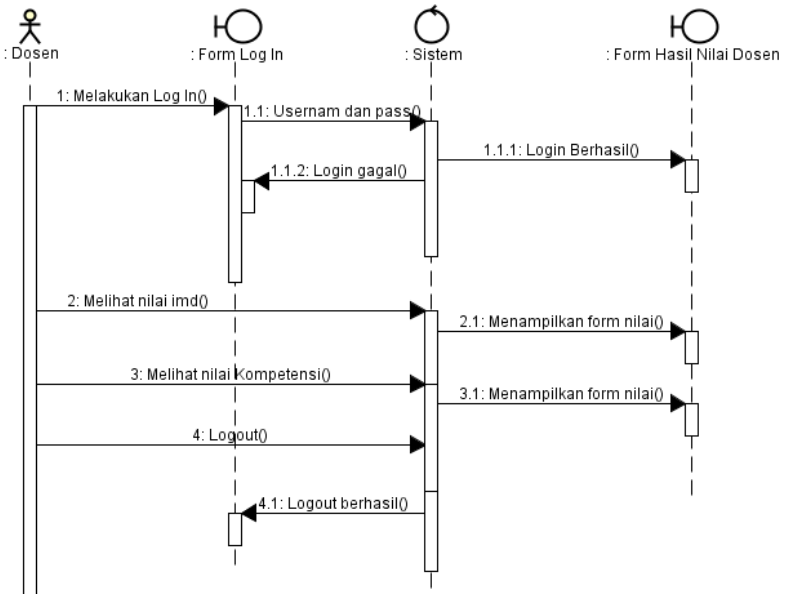

Gambar 8 Sequence Diagram Sistem Pada Dosen

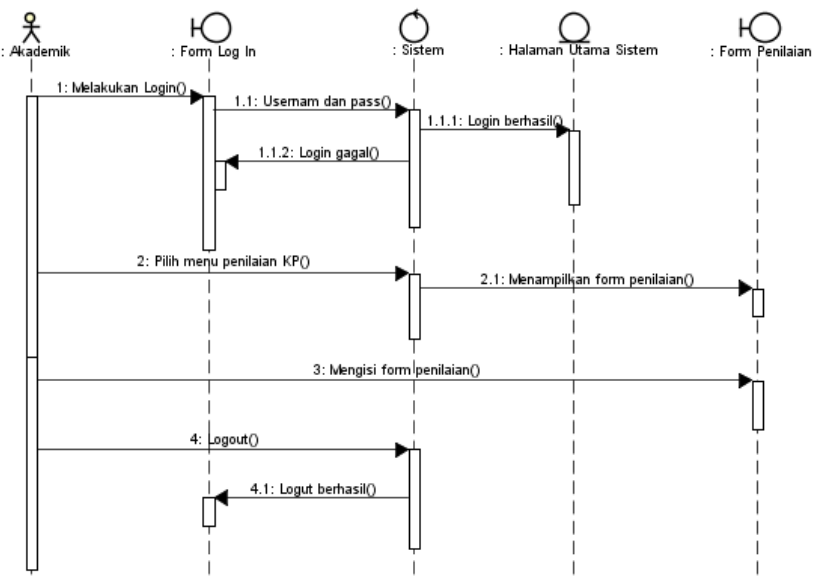

Gambar 9 Sequence Diagram Sistem Pada Akademik

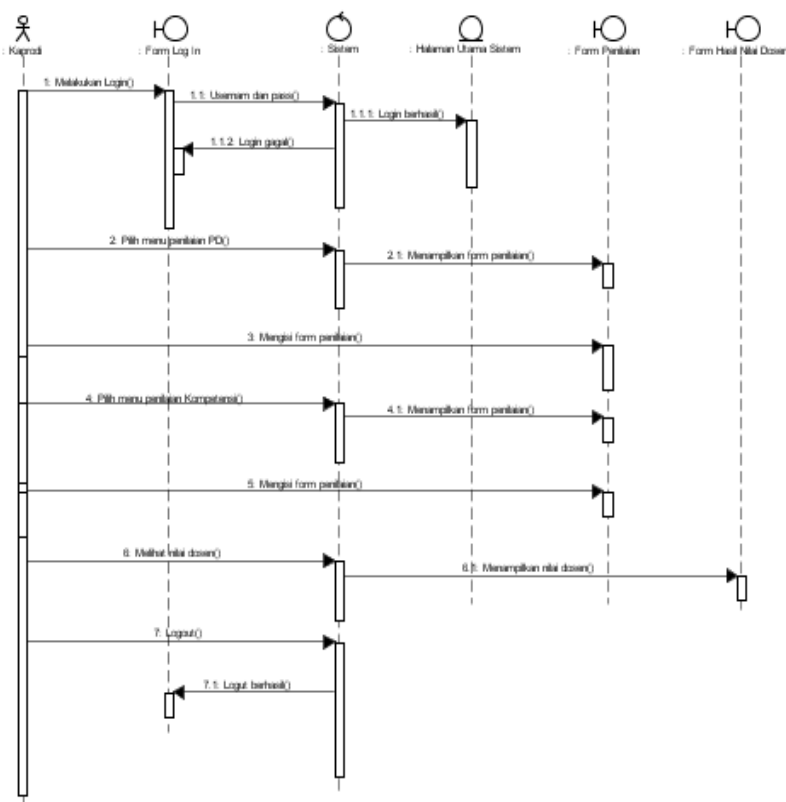

Gambar 10 Sequence Diagram Sistem Pada Kaprodi 
Pada gambar 10 merupakan interaksi kaprodi dengan objek yang ada pada sistem, di mana kaprodi melakukan login, sistem akan menampilkan form penilaian, kaprodi dapat melakukan penilaian, melihat hasil nilai dosen, dan keluar dari sistem.

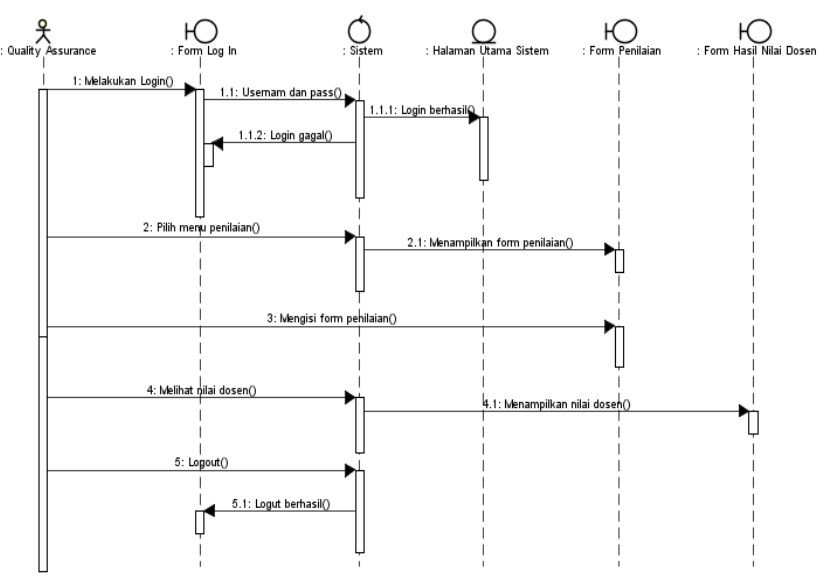

Gambar 11 Sequence Diagram Sistem Pada Quality Assurance

Pada gambar 11 merupakan interaksi quality assurance (QA) dengan objek yang ada pada sistem, di mana quality assurance melakukan login, sistem akan menampilkan form penilaian, quality assurance dapat memasukkan nilai dosen, melihat hasil nilai dosen, dan keluar dari sistem.

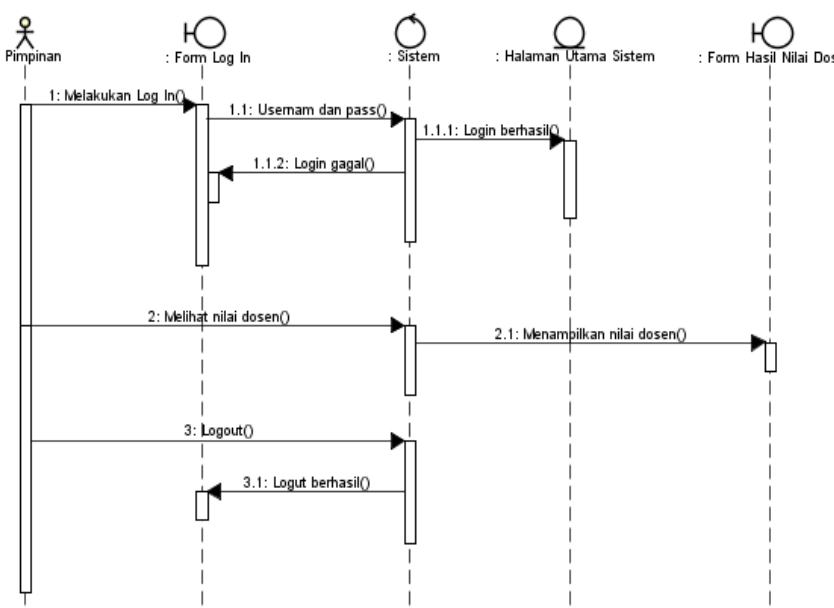

Gambar 12 Sequence Diagram Sistem Pada Pimpinan

Pada gambar 12 merupakan interaksi pimpinan dengan objek yang ada pada sistem, di mana pimpinan melakukan login, sistem akan menampilkan form nilai dosen, pimpinan dapat melihat hasil nilai dosen, dan keluar dari sistem.

\section{ANALISIS DAN PEMBAHASAN Pengujian Algoritma $\mathrm{K}$-Means}

Penentuan rekomendasi dosen tetap berdasarkan indeks mengajar dosen, dan nilai kompetensi, Dosen yang memiliki jumlah indeks mengajar dosen yang lebih dari 1 akan dicari nilai rata-rata terlebih dahulu sebelum melakukan pengelompokan. Data yang ada ditentukan nilai centroid, jumlah centroid berdasarkan jumlah kategori yang akan dikelompokkan. Tentukkan nilai titik cluster untuk melakukan clustering, nilai cluster ditentukkan secara acak. Dibawah ini adalah Tabel 1 nilai titik cluster awal:

Tabel 1 Nilai Titik Cluster Awal

\begin{tabular}{|c|c|c|c|}
\hline Kategori & Titik & Indeks & Kompetensi \\
\hline Layak & Cluster 1 & 2.94 & 66 \\
\hline Tidak Layak & Cluster 2 & 1.59 & 43 \\
\hline
\end{tabular}

Proses cluster dilakukan berulang kali sampai posisi cluster tidak melakukan perpindahan ke titik yang lain.

Tabel 2 Hasil Clustering

\begin{tabular}{|c|c|c|c|c|c|}
\hline No & Kode & IMD & $\begin{array}{c}\text { Kompetens } \\
\text { i }\end{array}$ & Posisi & Kategori \\
\hline 1 & L0048 & 1.59 & 43 & $\mathrm{C} 2$ & $\begin{array}{l}\text { Tidak } \\
\text { Layak }\end{array}$ \\
\hline 2 & L0039 & 1.71 & 43 & $\mathrm{C} 2$ & $\begin{array}{l}\text { Tidak } \\
\text { Layak }\end{array}$ \\
\hline 3 & L0034 & 1.72 & 47 & $\mathrm{C} 2$ & $\begin{array}{l}\text { Tidak } \\
\text { Layak }\end{array}$ \\
\hline 4 & L0035 & 1.8 & 42 & $\mathrm{C} 2$ & $\begin{array}{l}\text { Tidak } \\
\text { Layak }\end{array}$ \\
\hline 5 & L0013 & 1.97 & 51 & $\mathrm{C} 2$ & $\begin{array}{l}\text { Tidak } \\
\text { Layak }\end{array}$ \\
\hline 6 & L0042 & 2.07 & 54 & $\mathrm{C} 2$ & $\begin{array}{l}\text { Tidak } \\
\text { Layak }\end{array}$ \\
\hline 7 & L0038 & 2.09 & 57 & $\mathrm{C} 2$ & $\begin{array}{l}\text { Tidak } \\
\text { Layak }\end{array}$ \\
\hline 8 & L0032 & 2.14 & 44 & $\mathrm{C} 2$ & $\begin{array}{l}\text { Tidak } \\
\text { Layak }\end{array}$ \\
\hline 9 & L0024 & 2.2 & 46 & $\mathrm{C} 2$ & $\begin{array}{r}\text { Tidak } \\
\text { Layak }\end{array}$ \\
\hline 10 & L0026 & 2.23 & 57 & $\mathrm{C} 2$ & $\begin{array}{l}\text { Tidak } \\
\text { Layak }\end{array}$ \\
\hline $\begin{array}{c}\cdots \cdots \\
\quad . \\
\end{array}$ & .......... & $\begin{array}{c}\ldots \ldots \ldots \\
. \\
\end{array}$ & & & \\
\hline 62 & L0054 & 2.93 & 78 & $\mathrm{C} 1$ & Layak \\
\hline 63 & L0005 & 2.94 & 66 & $\mathrm{C} 2$ & $\begin{array}{r}\text { Tidak } \\
\text { Layak } \\
\end{array}$ \\
\hline 64 & L0068 & 3.01 & 75 & $\mathrm{C} 1$ & Layak \\
\hline 65 & L0046 & 3.04 & 69 & $\mathrm{C} 1$ & Layak \\
\hline 66 & L0065 & 3.13 & 83 & $\mathrm{C} 1$ & Layak \\
\hline 67 & L0047 & 3.14 & 73 & $\mathrm{C} 1$ & Layak \\
\hline \multicolumn{6}{|l|}{68} \\
\hline 69 & L0066 & 3.17 & 89 & $\mathrm{C} 1$ & Layak \\
\hline 70 & L0006 & 3.18 & 72 & $\mathrm{C} 2$ & $\begin{array}{l}\text { Tidak } \\
\text { Layak }\end{array}$ \\
\hline
\end{tabular}

Data uji yang digunakan dalam penelitian ini berjumlah 70 data hasil penilaian kinerja dosen pada sistem. Di mana data yang di cluster berdasarkan indeks mengajar dosen dan 
kompetensi dosen untuk mengetahui seorang dosen layak menjadi dosen tetap atau tidak. Dari 70 data yang diuji terdapat 39 data dosen yang dapat direkomendasi layak menjadi dosen tetap dan 31 data dosen yang tidak layak direkomendasi menjadi dosen tetap. Dalam hasil perhitungan akurasi, didapatkan presentase sebesar $55.67 \%$ dari 70 data hasil penilaian yang didapatkan oleh dosen.

\section{Kesimpulan}

Kesimpulan yang didapatkan dari hasil penelitian adalah sebagai berikut:

1. Dari hasil pengujian diatas, didapatkan hasil rekomendasi dosen tetap dengan kategori layak pada proses clustering sebesar 55\% tingkat keberhasilan, dengan jumlah 39 data dosen tetap yang layak dari 70 data dosen yang di cluster sehingga dapat disimpulkan bahwa algoritma $K$ Means Clustering tidak cocok digunakan pada studi kasus ini.

\section{Saran}

Aplikasi dapat dikembangkan menggunakan proses klasifikasi untuk mendapatkan hasil yang lebih akurat berdasarkan data clustering yang ada. Aplikasi diharapkan dapat digunakan dalam basis mobile.

\section{Daftar Pustaka}

Hendini, A. (2016). Pemodelan UML Sistem Informasi Monitoring Penjualan Dan Stok Barang (Studi Kasus : Distro Zhezha Pontianak). Jurnal Khatulistiwa Informatika, vol. IV, no. 2, pp. 107-1016.

J. O. Ong, "Implementasi Algoritma K-means Clustering Untuk Menentukan Strategi Marketing President University," Jurnal Ilmiah Teknik Industri, vol. 12, no. 1, pp. 10-20, 2013.

M. Rosmiati, "Analisis dan Perancangan E-Service Untuk Pelanggan Pada Jaya Bersama Konveksi," Indonesian Journal on Software Engineering, vol. 1, no. 1, pp. 1-7, 2015.

Muslihudin, M., Triananingsih, F., Kasmi, \& Anggraei, L. (2017). Pembuatan Model Penilaian Indeks
Kinerja Dosen Menggunakan Metode Fuzzy Simple Additive Weighting. Seminar Nasional Teknologi Informasi dan Multimedia, 5(1), 2530.

Muzakir, A. (2014). Analisa Dan Pemnafaatan Algoritma K-Means Clustering Pada Data Nilai Siswa Sebagai Penentuan Penerimaan Beasiswa. Prosiding Seminar Nasional Aplikasi Sains \& Teknologi, 195-200.

Nagesh, A. S., \& Satyamurty, C. V. (2018). Aplication of Clustering Algorithm for Analysis of Student Academic Performance. Internasional Journal of Computer Science and Egineering, 6(1), 381-384.

Nasari, F., \& Darma, S. (2015). Penerapan K-Means Clustering Pada Data Penerimaan Mahasiswa Baru. Seminar Nasional Teknologi Informasi dan Multimedia, 73-78.

Parlina, I., Windarto, A. P., Wanto, A., \& Lubis, M. R. (2018). Memanfaatkan Algoritma K-Means Dalam Menentukan Pegawai Yang Layak Mengikuti Asessment Center Untuk Clustering Program SDP. Journal of Computer Engineering System and Science, 3(1), 87-93.

Purnamasari , I., \& Afnisari, K. (2018). Performasi Klasifikasi Dosen Berprestasi Menggunakan Metode Naive Bayes Classifier. Jurnal Komputer dan Informatika Akademi Bina Sarana Informatika, $X X(2), 45-50$.

Raval, U. R., \& Jani, C. (2016). Implementasi \& Improvisation of K-Means Clustering Algorithm. Internasional Journal of Computer Science and Mobile Computing, 55(5), 191203.

Santoso and R. Nurimalina, "Perencanaan dan Pengembangan Aplikasi Absensi Mahasiswa Menggunakan Smart Card Guna Pengembangan Kampus Cerdas (Studi Kasus Politeknik Negeri Tanah Laut)," Jurnal Integrasi, vol. 9, no. 1, pp. 84-91, 2017.

Wahyuningtyas, E. U., Putri, R. M., \& Sutrisno. (2018). Optimasi K-Means Untuk Clustering Dosen Berdasarkan Kinerja Akademik Menggunakan Algoritma Genetika Paralel. Jurnal Pengembangan Teknologi Informasi dan Ilmu Komputer, 2(8), 2628-2635. 